\title{
Electrophysiological correlates of presynaptic opiate receptor activation: reduction in norepinephrine-mediated inhibition from the locus coeruleus
}

\author{
Hylan C. Moises \\ Department of Physiology, University of Michigan, Ann Arbor, MI 48109 (U.S.A.)
}

(Accepted 10 March 1987)

Key words: Morphine; Presynaptic opiate receptor; Locus coeruleus; Purkinje cell; Norepinephrine; $\gamma$-Aminobutyric acid; Inhibition

\begin{abstract}
Inhibitory responses of rat cerebellar Purkinje cells to locus coeruleus (LC) stimulation and iontophoresis of norepinephrine (NE) were examined before and after administration of morphine to determine whether the inhibitory modulation of NE release by opiates results in a functional impairment in noradrenergic synaptic action. Administration of morphine systemically $(0.2-1.2 \mathrm{mg} / \mathrm{kg}, \mathrm{i} . \mathrm{v}$.) or by iontophoresis reduced inhibitions in Purkinje firing elicited by LC stimulation without affecting depressions in activity induced by postsynaptic applications of NE. This antagonistic effect of morphine on LC-induced inhibition was reversed or prevented by naloxone and mimicked by administration of levorphanol but not dextrorphan. Morphine increased the excitatory response of Purkinje cells to monosynaptic input from the parallel fibers, whereas it blocked $\gamma$-aminobutyric acid-induced inhibitions in firing via a nonopiate receptor-mediated mechanism. These results demonstrate that morphine interferes with synaptic inhibition derived from the $\mathrm{LC}$ and suggest that this may occur via activation of presynaptic opiate receptors residing on noradrenergic nerve terminals.
\end{abstract}

\section{INTRODUCTION}

Opioids and opiate alkaloids such as morphine are known to have depressant effects on central noradrenergic neurotransmission. Studies in vitro have consistently demonstrated an inhibitory effect of morphine and opioid peptides on the release of norepinephrine (NE) from nerve terminals of locus coeruleus (LC) noradrenergic neurons following electrical stimulation of cortical, hypothalamic and cerebellar slices ${ }^{17,22,30,36}$. This action, which is stereospecific in nature ${ }^{36}$, is reversibly antagonized by naloxone $\mathrm{e}^{22,30,36}$, and has been attributed to the activation of presynaptic opiate receptors located on the axonal endings of LC neurons ${ }^{17,23}$. Opiate receptors are also located on the cell bodies of noradrenergic neurons in the $\mathrm{LC}^{1,28}$. Recent electrophysiological investigations have shown that the activation of these recep- tors results in hyperpolarization of LC neurons by increasing membrane conductance to potassium ${ }^{27,39}$, and it has been suggested by some workers that presynaptic opiate receptors may exert their inhibitory effect on NE release through a similar mechanism, involving hyperpolarization of preterminal processes leading to blockade of nerve impulse propagation and/or reduced calcium influx at noradrenergic nerve endings ${ }^{25}$. Consistent with this mode of action are the results of Nakamura and co-workers ${ }^{24}$ who demonstrated that the local infusion of opiates into the frontal cortical terminal fields of LC noradrenergic neurons decreased antidromic excitability of the axonal terminals to direct electrical stimulation.

Despite an abundance of in vitro evidence that opiates exert presynaptic inhibitory control of NE release from LC nerve terminals, few studies have demonstrated the physiological significance of this

Correspondence: H.C. Moises, Department of Physiology, University of Michigan, Ann Arbor, MI 48109, U.S.A. 
effect on the functional activity of intact noradrenergic synapses within the mammalian brain. To date, only Sasa and co-workers ${ }^{29}$ have provided evidence for a functional blockade of the response of LC target neurons to synapticaly released NE as a result of inhibitory modulation of presynaptic transmitter release by opiates. These workers showed in the cat that intravenous administration of morphine selectively interfered with NE-mediated inhibition of spinal trigeminal nucleus neurons induced by electrical stimulation of the LC. The objective of the present study was to determine whether similar effects occur in other target neurons of LC noradrenergic synaptic action as a result of activation of presynaptic opiate receptors.

The pathway from LC to Purkinje cells in rat cerebellum provides a favorable system for such an analysis, since in addition to anatomical demonstrations of a monosynaptic connection ${ }^{4,15,40}$, electrophysiological studies indicate that the inhibitory response of Purkinje cells to both LC stimulation and microiontophoresis of NE reflects a direct hyperpolarizing action of the catecholamine $e^{2,12,33,34}$. In addition, the opiate receptors that are present in rat cerebellum appear largely to reside presynaptically on the noradrenergic fibers innervating the region ${ }^{10.18}$, which should reduce the possibility of confounding effects resulting from an interaction of exogenously administered opiates at sites remote from LC-to-Purkinje cell synapses. This study was designed to characterize the effects of systemic and microiontophoretic administration of morphine on LC-mediated synaptic inhibition of Purkinje cells. The results demonstrate that morphine selectively interferes with LC-mediated Purkinje inhibition and suggest that this occurs via activation of presynaptic opiate receptors residing on noradrenergic nerve endings.

\section{MATERIALS AND METHODS}

Experiments were carried out on 34 male adult Sprague-Dawley rats, weighing $250-350 \mathrm{~g}$. Animals were initially anesthetized with $2.5 \%$ halothane in air, tracheostomized and the jugular vein was cannulated. The animal was then fixed in a stereotaxic instrument and a craniotomy was performed to expose the vermis and pars intermedia of the posterior cerebellum. The dura was excised and the exposed corti- cal surface covered with gelled agar in balanced salt solution to prevent drying. Body temperature was held constant at $37^{\circ} \mathrm{C}$ by means of a servo-control unit. Prior to recording, the halothane concentration was reduced to $0.5-0.75 \%$ in air and maintained at that level for the remainder of the experiment. All wound edges and pressure points were infiltrated with $2 \%$ procaine hydrochloride solution on a regular basis throughout the experiment.

Five-barreled glass micropipettes with 3-6 $\mu \mathrm{m}$ tips were used to record extracellularly from single Purkinje cells and to apply chemical substances at the site of recording by microiontophoresis. The center barrel, filled with $4 \mathrm{M} \mathrm{NaCl}$ or a solution of $2 \mathrm{M} \mathrm{NaCl}$ saturated with Fast green dye, was used for recording. Three side barrels were back-filled with various combinations of the following solutions: 1-norepinephrine- $\mathrm{HCl} 0.5 \mathrm{M}, \mathrm{pH} 4.5$ (Sigma); $\gamma$-aminobutyric acid (GABA) $0.1 \mathrm{M}$, pH 3.5 (Sigma); morphine sulfate $50 \mathrm{mM}$, pH 5.0 (Mallinckrodt); naloxone- $\mathrm{HCl}$ $50 \mathrm{mM}$ dissolved in $100 \mathrm{mM} \mathrm{NaCl}, \mathrm{pH} 5.0$ (Endo Laboratories). Drug solutions were ejected as cations or retained by application of $15 \mathrm{nA}$ currents of opposite polarity. Automatic current balancing was maintained through an additional peripheral barrel containing $3 \mathrm{M} \mathrm{NaCl}$. Controls for current artifacts and $\mathrm{pH}$ or local anesthetic effects of drug were as previously described ${ }^{11,21}$.

The coeruleus-cerebellar noradrenergic pathway was activated by electrical stimulation through a concentric bipolar electrode introduced stereotaxically into the ipsilateral LC nucleus (lateral $1.1 \mathrm{~mm}$, posterior $1.1 \mathrm{~mm}$; extrapolated from König and Klip$\left.\mathrm{pel}^{16}\right)$. In some experiments, electrical stimulation (one shock of 0.2 ms duration at a frequency of 0.3 $\mathrm{Hz}$ ) was also delivered to the cerebellar surface by means of a second electrode in order to elicit parallel fiber-induced excitations and 'off beam' inhibitions of Purkinje cell firing, mediated via input from GABA-containing cortical interneurons ${ }^{8}$. In this way the effects of opiate administration on LC-induced and non-noradrenergic synaptic inhibition could be examined on the same Purkinje neuron. Upon termination of an experiment, the position of the LC stimulating electrode was marked by passing a direct current of $20 \mu \mathrm{A}$ for $20 \mathrm{~s}$. The location of each stimulation site was verified histologically in $50 \mu \mathrm{M}$ frozen sections stained with Cresyl violet. 
Action potentials of Purkinje cells, identified by their characteristic discharge pattern of single and complex spikes ${ }^{8}$, were monitored on an oscilloscope, photographed and converted to uniform voltage pulses by a window discriminator. The pulses were integrated over 1-s intervals by a rate-meter and displayed on a strip chart recorder. From these gated pulses, poststimulus time histograms (PSTHs) were also constructed 'on-line' using an S120 Microeclipse computer (Data General Corporation).

Characterization of the extracellular responses of Purkinje cells to both transient and repetitive electrical stimulation of the ipsilateral LC was performed as described previously ${ }^{21}$. Briefly, the LC was first stimulated with 3 rectangular current pulses of $0.2 \mathrm{~ms}$ duration and $0.05-1.0 \mathrm{~mA}$ intensity, delivered every $3-5 \mathrm{~s}$ at a frequency of 50 or $100 \mathrm{~Hz}$. Unitary inhibitory responses of Purkinje cells to the LC stimulation were photographed and summed over 50-100 successive trials by the computer to generate a control PSTH for each neuron. PSTH records of the extracellular responses of Purkinje cells to cerebellar surface (LOC) stimulation were generated in a similar manner, except that single stimuli were delivered for each stimulation cycle. Stimulation sites within the LC were also tested for their ability to produce a long-lasting inhibition of the recorded neuron. All sites were stimulated with trains of $10-100$ current pulses of $0.1 \mathrm{~ms}$ duration at $10 \mathrm{~Hz}$ with intensities of 0.05-0.65 mA. Rate-meter records of unit activity were constructed (see above) and used to assess changes in spontaneous Purkinje cell discharge elicited by the repetitive stimulation.

Once the control response of a Purkinje cell to LC stimulation was established, the effects of administration of opiates on the synaptically induced inhibition were examined. In about half the animals, testing was first carried out using microiontophoresis to administer morphine and other chemical agents locally in the immediate extracellular vicinity of the Purkinje neuron under study. Upon the completion of these studies and in all remaining animals, morphine sulfate, or else levorphanol or dextrorphan, was administered intravenously at an initial dosage of 0.2 or $0.5 \mathrm{mg} / \mathrm{kg}$, respectively, with additional increments of similar dosage delivered as needed at 5-min intervals up to a total maximum dosage of $4.0 \mathrm{mg} / \mathrm{kg}$. Rate-meter and/or PSTH records were computed during each period of iontophoretic or systemic drug application to quantify any change in the Purkinje cell inhibitory response to LC activation. Similar records were constructed following administration of naloxone to test for specific blockade or reversal of opiate effects by the antagonist. To avoid residual drug effects, only one cell in each animal was studied following the systemic injection of opiate agonists or antagonists.

The effects of opiate administration on LC-induced inhibition of Purkinje cells were assessed by comparing the discharge rates in identical portions of the inhibitory response epoch from histograms computed during control and drug application periods and by qualitative examination of corresponding rate-meter records (see ref. 20). For each cell, periods of spontaneous discharge and of activity during the inhibitory response were identified in the PSTHs. With the aid of the computer, the discharge rates in these epochs were calculated and the response to LC stimulation was expressed as a percentage inhibition of the baseline rate of Purkinje cell spontaneous firing. The total duration of synaptically induced inhibition was also determined from the PSTH records. Differences in the mean magnitude or duration of the LC-induced inhibitory response elicited during control periods and following opiate administration were evaluated statistically by means of a two-tailed Student's $t$-test.

\section{RESULTS}

\section{Effects of LC stimulation on Purkinje cell discharge}

Extracellular responses to electrical stimulation in the region of the LC were examined in 49 Purkinje cells in the vermal region and pars intermedia of lobules VI and VII. Stimulation of the LC with short bursts of 3 pulses at high frequencies $(50-100 \mathrm{~Hz})$ resulted in depression of spontaneous activity in 42 of the neurons. These inhibitory responses consisted of either a reduced probability or complete cessation of spike discharge lasting for periods of $125-580 \mathrm{~ms}$ (mean, $366 \mathrm{~ms}$ ) with latencies to onset of $62-189 \mathrm{~ms}$ (mean, $144 \mathrm{~ms}$ ). In addition, in all but two of the 42 neurons, stimulation of the LC with trains of $10-50$ pulses, delivered at a pulse frequency of $10 \mathrm{~Hz}$, produced prolonged slowing or cessation of spontaneous 
A

\section{LC Inhibition}

Control
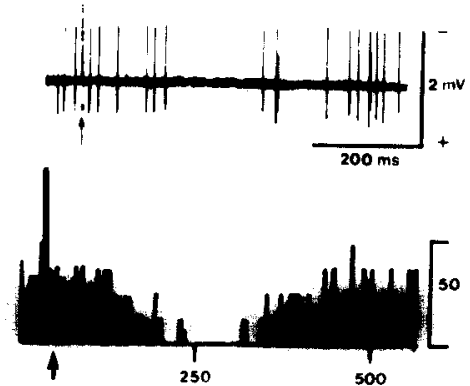

B

\section{LC Inhibition}

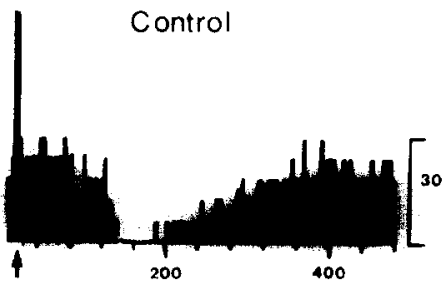

2 Off-Beam Inhibition

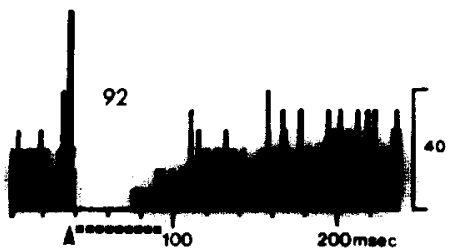

Morphine $0.2 \mathrm{mg}$
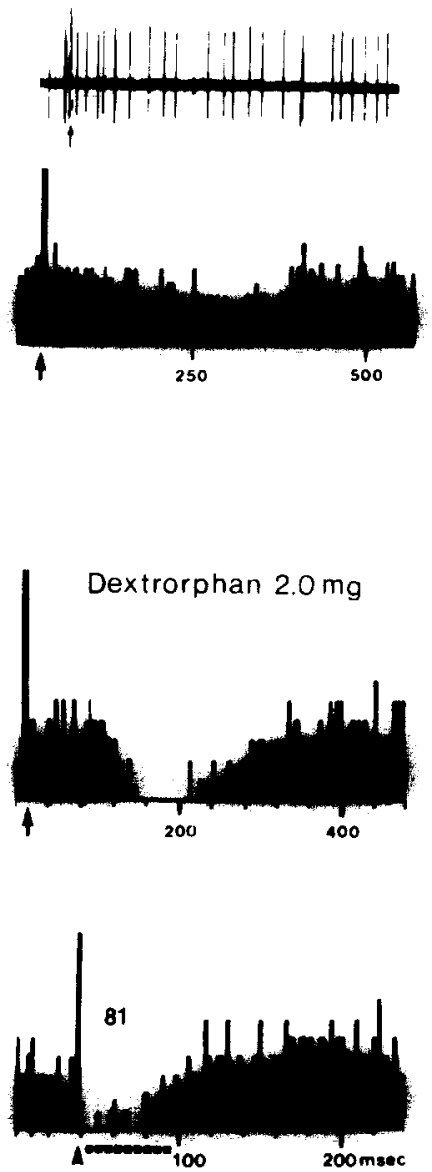

Naloxone $0.2 \mathrm{mg}$
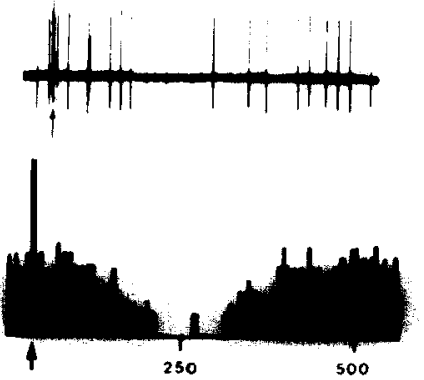
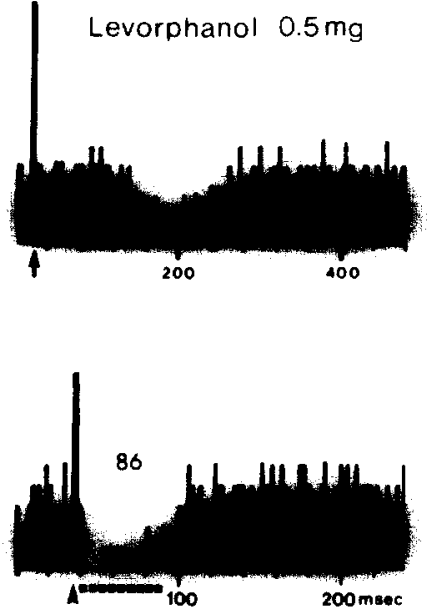

Fig. 1. Comparison of the effects of opiates on LC-induced and GABA-mediated synaptic inhibition of cerebellar Purkinje cells. A: the extracellular spike (upper) and PSTH records (lower) show the depressant effect of morphine, $0.2 \mathrm{mg} / \mathrm{kg} \mathrm{i.v.,} \mathrm{on} \mathrm{LC-induced} \mathrm{in-}$ hibitions in firing. Administration of naloxone, $0.2 \mathrm{mg} / \mathrm{kg}$ i.v., reversed the effects of morphine and restored the inhibitory effect of LC stimulation to near control levels. B: PSTH records illustrate the differential effects of systemic administration of dextrorphan and levorphanol on LC-indaced $\left(B_{1}\right)$ and off-beam inhibiton $\left(B_{2}\right)$ in another Purkinje cell. Administration of $0.5 \mathrm{mg} / \mathrm{kg}$ levorphanol, but not dextrorphan up to a total dose of $2.0 \mathrm{mg} / \mathrm{kg}$, reduced the inhibitory effect of LC stimulation, whereas neither drug affected inhibitions in firing elicited by off-beam stimulation of the cerebellar surface. LC stimulations in A and B consisted of 3 shocks at $50 \mathrm{~Hz}$, delivered at $0.5 \mathrm{~Hz}$ frequency and at 0.25 and $0.35 \mathrm{~mA}$ intensity, respectively. The cerebellar surface was stimulated with single shocks of 0.4 $\mathrm{mA}$ intensity every $3 \mathrm{~s}$ to elicit off-beam inhibitions of spontaneous discharge. Fifty consecutive trials were summed to generate each histogram. Vertical peaks above the arrows in these and subsequent histogram records represent the inclusion of counts from shock artifacts due to stimulus presentations. Numbers above histogram records in $\mathrm{B}_{2}$ provide quantitation of the response as a percentage inhibition of baseline activity. Vertical calibrations for histogram records are in counts per bin.

discharge which outlasted the period of stimulation by 3-16 s. Typical examples of the inhibitory response of a Purkinje cell to short bursts of LC stimuli are shown in the oscilloscope and PSTH records of Figs. $1 \mathrm{~A}$ and $2 \mathrm{~A}$ (oscilloscope specimens only). The rate-meter record in Fig. 2B illustrates the prolonged inhibitory effect of repetitive LC stimulation in another neuron. It should be noted that the depressions in Purkinje cell discharge produced by LC stimulation in the present study conformed closely to inhibitory events previously associated with LC activation $^{12.21 .33}$ 
Effects of opiate administration on LC-induced inhibition of Purkinje cells

The effects of systemic adminstration of morphine on inhibitory responses of Purkinje cells to LC activation were examined in 18 neurons. In 15 of the neurons, administration of $0.2-0.8 \mathrm{mg} / \mathrm{kg}$ morphine, i.v., markedly reduced and in some cases $(n=6)$ abolished inhibitions in spike discharge elicited by stimulation of the LC with short bursts of stimuli
(Table I). The administration of morphine in a similar range of doses $(0.2-1.2 \mathrm{mg} / \mathrm{kg}$ ) also reduced the magnitude and duration of inhibitions in firing produced by repetitive $10 \mathrm{~Hz}$ stimulation of the LC in 7 out of 10 Purkinje cells tested from this same group (Fig. 2B). The reduction in LC-induced inhibitory action produced by morphine varied directly in relation to the dosage of the narcotic administered. In addition, blockade was typically observed $(n=12$ cells)

A

Control

Naloxone $0.1 \mathrm{mg}$
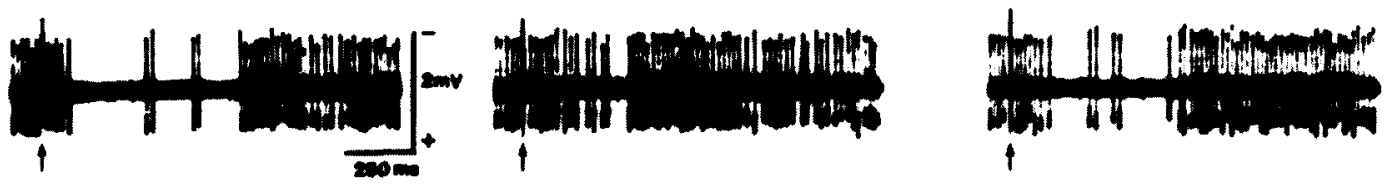

B

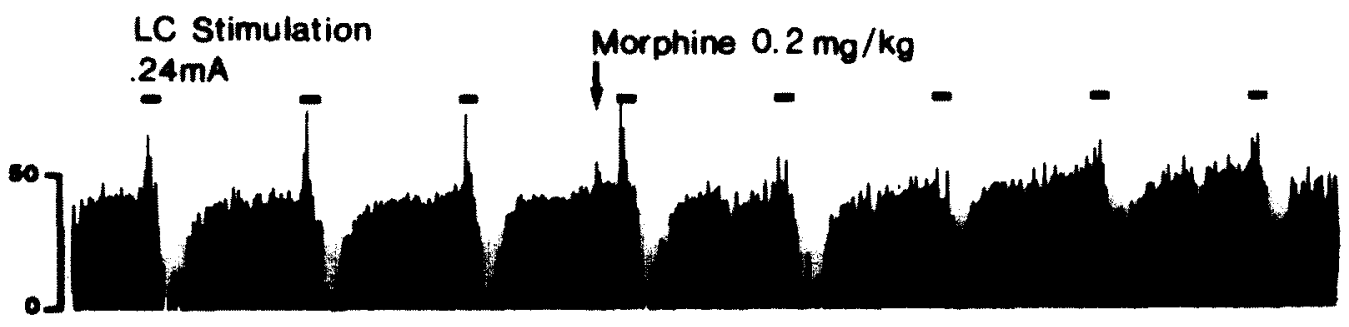

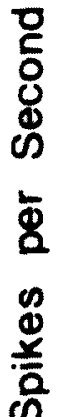
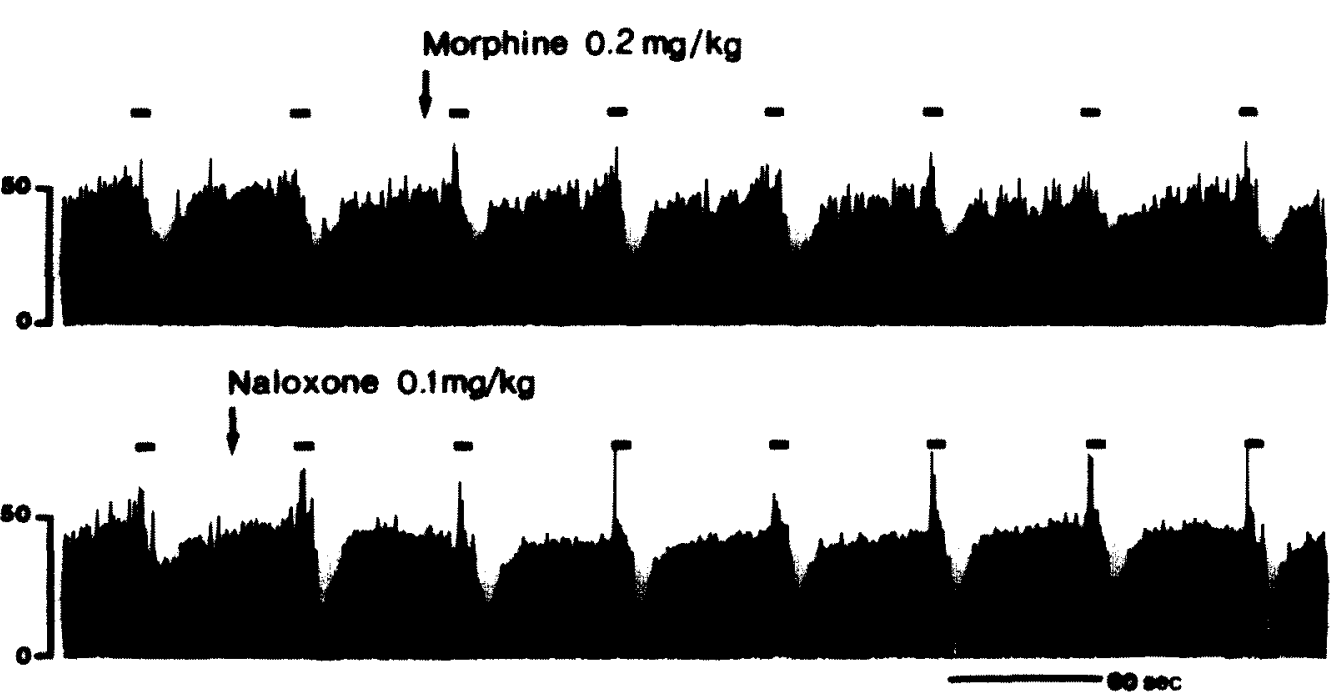

Fig. 2. Depressant effect of morphine on long-lasting inhibition of a cerebellar Purkinje cell elicited by repetitive stimulation of the LC. A: extracellular spike records show a reduction of the inhibitory response of the cell to brief presentations of LC stimuli ( 3 shocks of $0.24 \mathrm{~mA}$ intensity delivered every $3 \mathrm{~s}$ at $50 \mathrm{~Hz}$ ) after morphine administration, $0.2 \mathrm{mg} / \mathrm{kg}$ i.v. (middle panel), and reversal of the opiate action by $0.1 \mathrm{mg} / \mathrm{kg}$ naloxone (right panel). B: continuous rate-meter records show the prolonged inhibitory response of the same neuron to $10 \mathrm{~Hz}$ stimulation of the LC, delivered for $7 \mathrm{~s}$ at $0.24 \mathrm{~mA}$ intensity before and after i.v. administration of morphine. The inhibitory effect of LC stimulation was reduced by morphine in a dose-dependent manner, but recovered quickly to near control levels after the administration of $0.1 \mathrm{mg} / \mathrm{kg}$ naloxone. Bars over rate-meter records indicate the period and duration of $\mathrm{LC}$ stimulation. 
TABLE I

Effect of opiates on noradrenergic inhibition of Purkinje cells

\begin{tabular}{|c|c|c|c|c|c|}
\hline \multirow[t]{3}{*}{ Opiate } & \multirow{3}{*}{$\begin{array}{l}\text { Number of } \\
\text { cells tested }\end{array}$} & \multicolumn{4}{|c|}{ Effect on noradrenergic inhibition } \\
\hline & & \multicolumn{2}{|l|}{ Blockade } & \multirow[t]{2}{*}{ Increase } & \multirow[t]{2}{*}{ No effect } \\
\hline & & Total cells & $\begin{array}{l}\text { Naloxone- } \\
\text { sensitive }\end{array}$ & & \\
\hline \multicolumn{6}{|l|}{ LC-induced inhibition } \\
\hline Morphine & 18 & 15 & 12 of 15 & 0 & 3 \\
\hline Levorphanol & 8 & 6 & & 0 & 2 \\
\hline Dextrorphan & 8 & 0 & & 1 & 7 \\
\hline Morphine iontophoresis & 12 & 8 & 3 of 5 & 1 & 3 \\
\hline \multicolumn{6}{|l|}{ NE-induced inhibition } \\
\hline Morphine & 20 & 2 & 0 of 2 & 2 & 16 \\
\hline Levorphanol & 6 & 0 & & 1 & 5 \\
\hline Dextrorphan & 4 & 0 & & 0 & 4 \\
\hline
\end{tabular}

at dosages of the narcotic which had little appreciable effect on the baseline discharge of the cell, as shown, for example, in Fig. 1A. Overall, changes in baseline discharge were observed in only 5 cells (increases in 3 cases, decreases in 2 cases) after administration of morphine in the dosage range $(0.2-1.2 \mathrm{mg} / \mathrm{kg})$ where blockade of LC-induced inhibition was achieved.

To determine whether the depressant effect of morphine on LC-mediated inhibition involved the activation of physiological opiate receptors, the specific opiate antagonist naloxone was administered in an attempt to reverse any observed effects of morphine. Administration of $0.1-0.2 \mathrm{mg} / \mathrm{kg}$ of the antagonist produced at least partial reversal $(42-100 \%$ range, $76.5 \%$ mean) of the depressant action of morphine on LC-induced inhibition in 12 out of 15 Purkinje cells tested (Table I). The effects of naloxone were apparent within $1 \mathrm{~min}$ of administration of the antagonist (Fig. 2), and appeared equipotent against morphine's action on both profiles of LC-induced Purkinje cell inhibition (cf. Figs. 1 and 2). Tests on 6 additional neurons revealed that administration of naloxone alone in the range of doses used to antagonize the effects of morphine had no significant effect on Purkinje cell inhibitory responses elicited by either short bursts ( $n=4$ cells) or trains of LC stimuli ( $n=6$ cells) (data not shown).

The involvement of opiate receptors in mediating the depressant effects of morphine on LC-induced inhibition was further assessed by characterizing the stereospecificity of this action using levorphanol and dextrorphan in place of morphine. The ability of levorphanol and of dextrorphan, its opiate inactive enantiomer, to block LC-induced inhibition of Purkinje cell discharge was compared in 16 neurons. Administration of levorphanol, $0.5-1.0 \mathrm{mg} / \mathrm{kg}$ i.v., reduced inhibitions in spike discharge produced by brief presentations of LC stimuli ( 3 shocks at $50 \mathrm{~Hz}$ ) in 6 out of 8 Purkinje cells tested (Table 1, Fig. 1B 1 ), thus mimicking the effect of morphine. In comparison, systemic administration of dextrorphan up to a total dosage of $4.0 \mathrm{mg} / \mathrm{kg}$ did not appreciably affect LC-induced inhibitory responses in 7 out of 8 additional Purkinje cells (Table I, Fig. $1 B_{1}$ ). This differential effect of levorphanol and dextrorphan was also observed in 3 experiments in which both agents were tested for their ability to reduce inhibitory responses to LC stimulation in the same neuron. In these experiments, dextrorphan was administered first in a dosage of $1.0 \mathrm{mg} / \mathrm{kg}$, followed by two supplemental injections of $0.5 \mathrm{mg} / \mathrm{kg}$, delivered 20 and 10 min prior to administration of levorphanol $(0.5$ $\mathrm{mg} / \mathrm{kg}$ ). The PSTH records in Fig. $1_{1}$ show the results of a typical experiment. In all 3 cases, a significant reduction in the inhibitory response to $\mathrm{LC}$ activation was only obtained after administration of levorphanol.

Site of opiate-induced depression of $L C$-mediated inhibition

Earlier reports of antagonistic effects of morphine on neuronal responses to $\mathrm{NE}^{5,32}$ raise the possibility 
A

LC-Inhibition
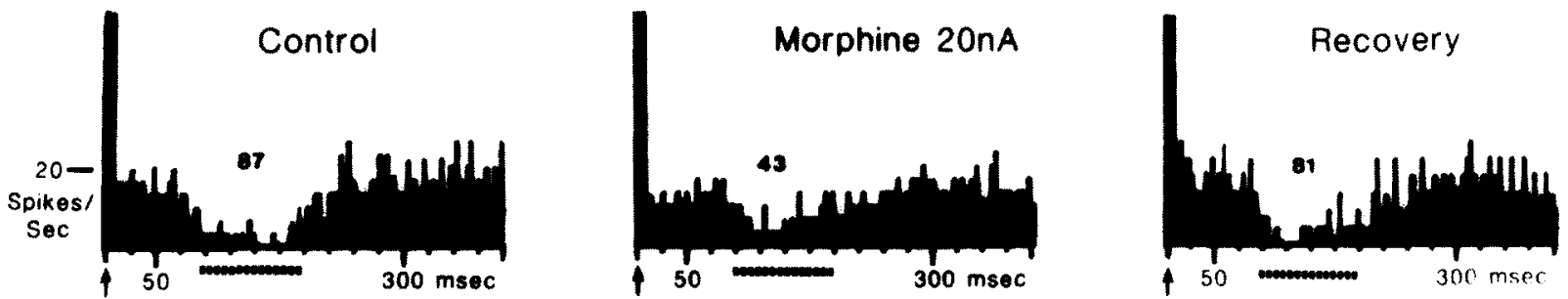

B

NE Iontophoresis

Morphine 40nA

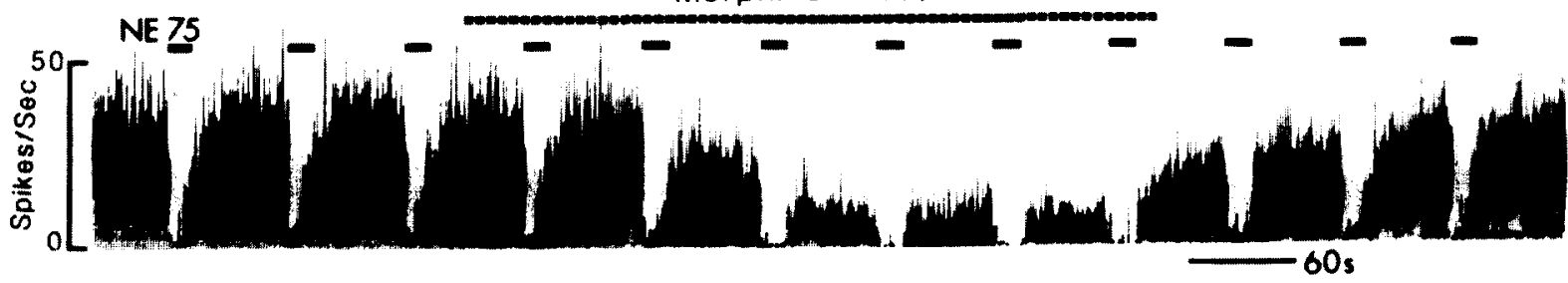

Fig. 3. Comparison of the effects of local administration of morphine on Purkinje cell inhibitions induced by LC stimulation and NE iontophoresis. A: PSTHs show a 50\% reduction in the inhibitory response (dashed line under records) of a cell to LC stimulation during iontophoresis of morphine $20 \mathrm{nA}$. Stimulus presentations consisted of 3 shocks of $0.25 \mathrm{nA}$ at $50 \mathrm{~Hz}$, delivered every $3 \mathrm{~s}$ and repeated 50 times for each histogram. B: continuous rate-meter record from the same neuron shows no effect of morphine iontophoresis 40 $\mathrm{nA}$ (dashed line) on inhibitions in firing produced by iontophoretic application of NE $75 \mathrm{nA}$ (solid bars) directly onto the cell. Note that a direct depressant effect of morphine iontophoresis on baseline discharge is apparent in the histogram and rate-meter records. Numbers above histogram records in A provide quantitation of LC-induced responses as a percentage inhibition of baseline activity.

that the narcotic may be acting at a postsynaptic site to block LC-induced inhibitory effects on Purkinje cells. To determine whether the observed blockade of LC-induced inhibition reflects an interaction of the opiate at a pre- or postjunctional site of the LC-Purkinje cell synapse, the effects of morphine administration on inhibitions in firing produced by iontophoretic application of NE were examined in 20 cells. Morphine was applied locally at the site of recording by iontophoresis in all cases, and in 4 cells the opiate was also administered systematically following the completion of iontophoretic testing. The effects of morphine iontophoresis on inhibitory responses to LC stimulation were concurrently assessed in 12 of the neurons.

Application of uniform current pulses at regular intervals through the NE-containing barrel of a micropipette produced consistent inhibitions of Purkinje cell discharge, as illustrated for the cell shown in Fig. 3B. During continuous iontophoretic administration of $40 \mathrm{nA}$ morphine onto this cell, the level of spontaneous activity was substantially decreased, whereas the magnitude and duration of the inhibitory response to pulsatile applications of NE was substantially unchanged. In comparison, the inhibitory response of the cell to transient stimulation of the LC ( 3 shocks at $50 \mathrm{~Hz}$ every $3 \mathrm{~s}$ ) was reduced by more than $50 \%$ (from 87 to $43 \%$ inhibition in firing) during iontophoresis of $20 \mathrm{nA}$ morphine (Fig. 3A). Overall, iontophoretic administration of morphine had little or no effect on NE-induced inhibitions in firing in 16 of the 20 Purkinje cells tested, even when the narcotic was ejected at current levels producing direct slowing of spike dischange (Table I.) Application of the opiate over a similar range of doses (10-50 nA) did, however, reduce LC-induced inhibitory effects in 8 of the 12 cells examined (Table I). The depressant effect of locally applied morphine on neuronal inhibition derived from the LC was reversibly blocked during concurrent iontophoresis of naloxone (10-20 


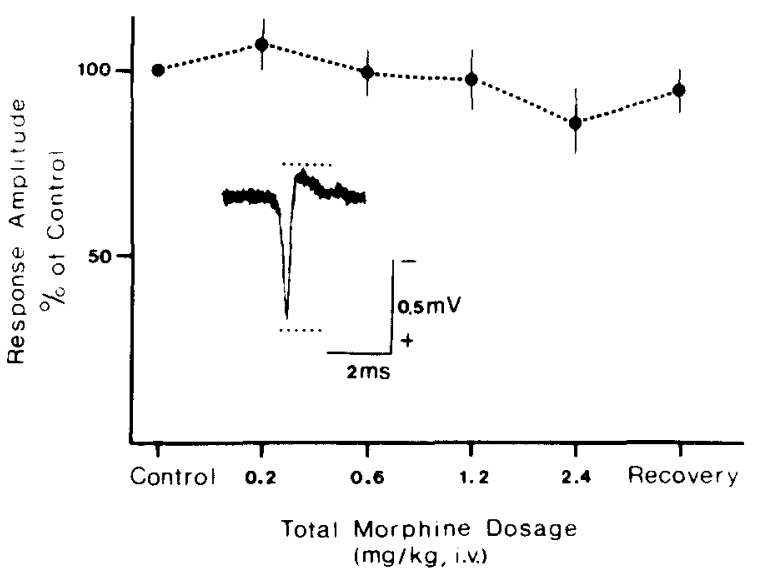

Fig. 4. Effect of morphine on the extracellular fiber potential recorded in the cerebellum after a single stimulation of the LC. Each point represents the mean amplitude of the evoked potential as a percent of the control response, measured from peak to peak (indicated by the dotted lines bracketing the potential shown in the inset). A small depression of the LC fiber potential was observed after administration of the highest dose of morphine $(2.4 \mathrm{mg} / \mathrm{kg})$, but this effect was not statistically significant $(P>0.5$, Student's $t$-test). The effects of morphine were assessed $5 \mathrm{~min}$ after each bolus injection of the narcotic and $30 \mathrm{~min}$ after the last drug injection for recovery. Vertical bar of each point indicates S.E.M. $(n=4)$.

$\mathrm{nA}$ ) in 3 out of 5 cells (Table I). Although an apparent blockade of NE-induced inhibition was observed in two cells during iontophoresis of morphine, this effect of the opiate was not reversible by naloxone (Table I). Moreover, inhibitory responses to NE application were not appreciably altered during iontophoresis of either levorphanol ( 5 out of 6 cells) or dextrorphan ( 4 out of 4 cells). Systemic administration of morphine, $0.2-1.0 \mathrm{mg} / \mathrm{kg}$, also had little effect on NE-induced inhibitions in firing in the 4 cells that were studied.

Opiate effects on monosynaptic excitations and GABA-mediated synaptic inhibitions of Purkinje cells

The finding that local application of morphine reduced inhibitions in Purkinje cell firing elicited by LC stimulation, but not by NE iontophoresis, suggests that the opiate is most likely acting presynaptically at LC nerve terminals to inhibit noradrenergic transmission. This would not rule out the possibility, however, that the reduction in LC inhibitory action produced by systemic administration of morphine might also reflect a non-specific blockade of nerve impulse conduction due to a narcotic action directly on axonal membranes ${ }^{31}$. In evaluating this possibility, it was found that morphine in the range of doses tested $(0.2-1.2 \mathrm{mg} / \mathrm{kg})$ did not affect the extracellular field potential recorded in the Purkinje cell layer after single stimulations of the LC (Fig. 4). However, because this evoked fiber potential appeared at times to represent a superimposition of effects, due in part to activation of other cerebellar afferents, it was considered important to also characterize narcotic effects on spike propagation along these non-noradrenergic pathways. This was accomplished by comparing the effects of morphine administration on the postsynaptic actions derived from activation of local nonadrenergic excitatory and inhibitory inputs to the Purkinje cell concurrently during characterization of the opiate's effects on LC-mediated inhibition.

Monosynaptic excitatory responses to input from the parallel fibers and inhibitions in firing elicited by activation of GABA-containing basket and stellate interneurons were obtained in 8 and 20 Purkinje cells, respectively, by recording 'on- and off beam' from a point of focal electrical stimulation (LOC stimulation) applied to the cerebellar surface ${ }^{8}$. The effect of systemic administration of morphine on the monosynaptic excitation of a Purkinje cell elicited by LOC stimulation of its parallel fiber input is illustrated in Fig. 5A. The response of this cell to LOC stimulation at $1.5 \times$ threshold consisted of a short latency ( $2 \mathrm{~ms}$ ) discharge of several spikes (peak in histograms) followed by a brief period of inhibition, attributable to the delayed activation of GABA-mediated input from local interneurons. During the control period, the excitatory response of this cell to parallel fiber activation was quantitated at 2.07 spikes per stimulus. Administration of morphine, 0.2-0.8 $\mathrm{mg} / \mathrm{kg}$, increased the excitatory response of the cell in a dose-dependent manner, whereas it resulted in a gradual reduction in the inhibitory period following the evoked excitation. Both of these effects of morphine were reversed after the administration of naloxone, $0.2 \mathrm{mg} / \mathrm{kg}$. This facilitating effect of morphine on parallel fiber synaptic action was also apparent in 5 out of 8 neurons when testing was done using lower intensities of LOC stimulation which limited the control excitation of the cell to single spike discharges (Table II). Administration of naloxone. $0.1-0.2 \mathrm{mg} / \mathrm{kg}$ i.v., reversed the enhancement of parallel fiber evoked discharge by morphine in two of these cases (Table II). 
A

Off-Beam Inhibition
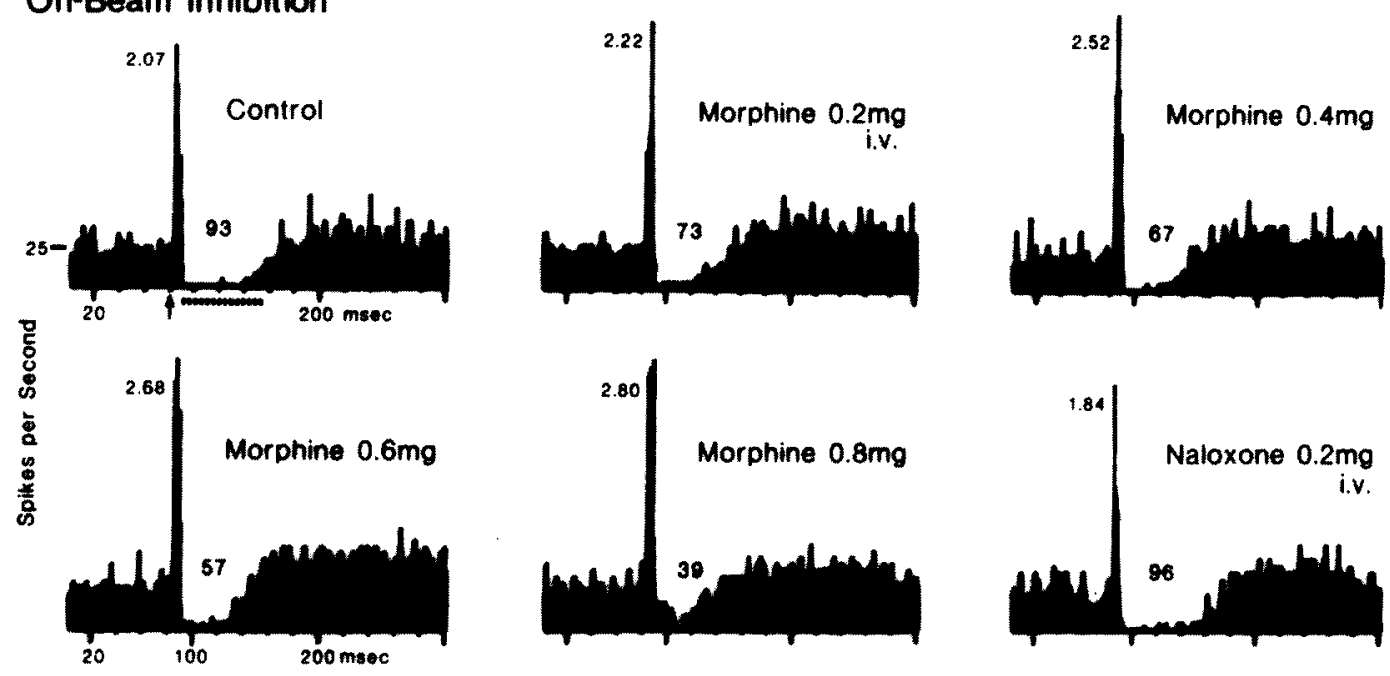

B
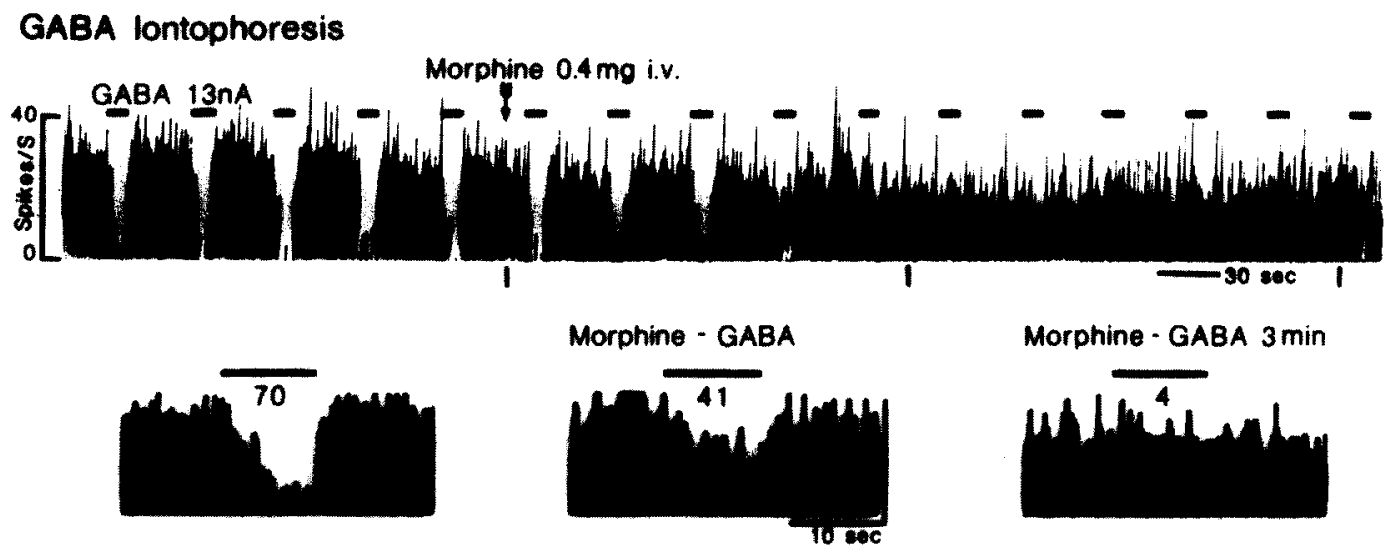

Fig. 5. Effects of systemic administration of morphine on Purkinje cell responses to monosynaptic excitatory and GABA-mediated inhibitory input and to GABA iontophoresis. PSTH records show a dose-dependent facilitation by morphine of the excitatory response (peaks in histograms) of a cell to activation of its parallel input. Administration of the opiate resulted in a concomitant reduction in postexcitatory inhibition (indicated by dashed line under first record) mediated by activation of input from local GABA-containing interneurons. Both actions of morphine were reversed after administration of $0.2 \mathrm{mg} / \mathrm{kg}$ naloxone. Numbers to the left and right of peaks in the histograms provide quantitation of the excitatory and inhibitory responses in spikes per stimulus and as a percentage inhibition of baseline activity, respectively. Responses to single shocks $(0.4 \mathrm{~mA}$ at $0.3 \mathrm{~Hz}$ frequency) to the cerebellar surface (applied at arrow) were summed over 50 consecutive trials to generate each histogram. B: Continuous rate-meter (upper) and corresponding drug-response histogram records (below) show blockade of the inhibitory response of another Purkinje cell to GABA iontophoresis, $13 \mathrm{nA}$ (solid bars), after administration of $0.4 \mathrm{mg} / \mathrm{kg}$ morphine. Each histogram contains 5 sweeps and corresponds to a particular segment of activity in the rate-meter record, indicated by the vertical bars. Vertical calibration for histograms in B indicates 30 spikes/s.

The effects of morphine administration on postsynaptic inhibitions in firing elicited by activation of local basket-stellate cell input were examined in 12 Purkinje cells. Intravenous administration of the narcotic $(0.2-1.6 \mathrm{mg} / \mathrm{kg})$ reduced or abolished LOC-induced inhibition in 10 neurons, while having no appreciable effect on off-beam inhibitory responses of two cells (Table II). The blockade of off-beam inhibition by morphine was partially reversed by administration of naloxone $(0.1-1.0 \mathrm{mg} / \mathrm{kg})$ in 4 of the 10 neurons tested (Table II). However, the action of the narcotic did not appear to be mediated by stereospecific opiate receptors, since neither levorphanol ( $n=4$ cells $)$ nor dextrorphan $(n=4$ cells $)$ altered in- 
TABLE II

Effect of opiates on Purkinje cell excitation and inhibition evoked by LOC stimulation

\begin{tabular}{|c|c|c|c|c|c|}
\hline \multirow[t]{2}{*}{ Opiate } & \multirow{2}{*}{$\begin{array}{l}\text { Number of } \\
\text { cells tested }\end{array}$} & \multicolumn{4}{|c|}{ Effect on LOC-induced response } \\
\hline & & Decrease & Increase & $\begin{array}{l}\text { Naloxone- } \\
\text { sensitive }\end{array}$ & No effect \\
\hline \multicolumn{6}{|c|}{ Parallel fiber excitation } \\
\hline Morphine & 8 & 0 & 5 & 2 of 5 & 3 \\
\hline \multicolumn{6}{|c|}{ Off-beam inhibition } \\
\hline Morphine & 12 & 10 & 0 & 4 of 10 & 2 \\
\hline Levorphanol & 4 & 0 & & & 4 \\
\hline Dextrorphan & 4 & 0 & & & 4 \\
\hline \multicolumn{6}{|c|}{ GABA-induced inhibition } \\
\hline Morphine & 10 & 8 & 0 & 3 of 8 & 2 \\
\hline Levorphanol & 4 & 0 & & & 4 \\
\hline Dextrorphan & 4 & 0 & & & 4 \\
\hline
\end{tabular}

hibitory responses to LOC stimulation in 8 additional cells (Fig. $1 \mathrm{~B}_{2}$ and Table II). Moreover, neither of these drugs had any appreciable effect on inhibitions in Purkinje cell firing induced by iontophoretic appliction of GABA, the putative basket-stellate cell neurotransmitter (Table II). This was in marked contrast to the effects of morphine administration which resulted in blockade of GABA-induced inhibition (Fig. 5B) in 8 of the 10 Purkinje cells in which offbeam inhibitory responses to LOC stimulation were also reduced (Table II).

\section{DISCUSSION}

\section{Reduction of LC-mediated inhibition by opiates}

It is well documented that neurons of the LC provide a monosynaptic innervation of NE-containing fibers to Purkinje cells in rat cerebellum ${ }^{4,12,15,26}$. These noradrenergic fibers synapse primarily on Purkinje cell secondary and tertiary dendrites and dendritic spines in the molecular layer, as demonstrated by fluorescence histochemistry ${ }^{26,40}$ and by electron microscopic autoradiographic ${ }^{4}$ and potassium permanganate fixation techniques ${ }^{15}$. Evidence from electrophysiological studies indicates that release of NE from these synaptic sites most likely accounts for the postsynaptic inhibitions in Purkinje cell firing that are recorded both intracellularly ${ }^{12,33}$ and extracellularly ${ }^{12,21,33}$ after electrical stimulation of the LC. These studies further reveal that the depressions in
Purkinje cell discharge elicited by LC stimulation are mediated directly via hyperpolarization of the postsynaptic membrane ${ }^{12,33,34}$ and that the effects of noradrenergic pathway activation are closely mimicked by iontophoresis of NE directly onto the neuron $^{2,11.34}$. Hence, the finding in the present study that morphine reduced inhibitions in Purkinje cell firing elicited by LC stimulation, without affecting responses to postsynaptic applications of NE, can be interpreted to reflect an outcome of inhibition by the opiate of synaptic release of NE. It seems unlikely that this depressant effect of morphine on LC-inhibitory action resulted simply from a non-specific blockade of nerve impulse conduction ${ }^{31}$, since administration of the narcotic had no appreciable effect on the field potential recorded in the Purkinje cell layer in response to single LC stimuli. Moreover, administration of morphine in dosages which reduced LC inhibitory action was found at times to enhance the efficacy of transmission of liminal parallel fiber input to Purkinje cells.

Autoradiographic studies of the binding of radiolabeled opiate agonists and antagonists in rat brain have consistently shown the presence, albeit in very low concentrations, of pharmacologically relevant opiate receptors in the cerebellum ${ }^{1.28 .35}$. These opiate receptors appear to be primarily localized presynaptically on the terminals of the LC noradrenergic neurons innervating this structure, as indicated by changes in the binding of $\left[{ }^{3} \mathrm{H}\right]$ naloxone in the cere- 
bellum following lesioning of NE-containing input from the LC. Llorens and co-workers ${ }^{18}$ have shown that destruction of LC noradrenergic neurons in adult rats by pretreatment with 6-hydroxydopamine results in a marked reduction ( $46 \%$ ) in the binding of $\left[{ }^{3} \mathrm{H}\right]$ naloxone in the cerebellum. Conversely, a substantial increase $(65 \%)$ in the number of cerebellar binding sites for $\left[{ }^{3} \mathrm{H}\right]$ naloxone has been reported to accompany the noradrenergic hyperplasia that occurs in the cerebellum after treatment of rats perinatally with the catecholamine neurotoxin ${ }^{10}$. The finding by Starke and co-workers ${ }^{22,36}$ that morphine, as well as enkephalins, inhibit the stimulation-evoked release of $\left[{ }^{3} \mathrm{H}\right] \mathrm{NE}$ from rat cerebellar slices also points to a presynaptic localization of opiate receptors on LC noradrenergic nerve terminals in this region.

Several lines of evidence indicate that the reduction in LC-mediated inhibition of Purkinje cell firing produced here by morphine reflects the activation of similar populations of 'presynaptic' opiate receptors. First, the depressant action of morphine on synaptic inhibition derived from the LC displayed the requisite features of an opiate receptor-mediated event. This action occurred at a range of systemic morphine dosages appropriate for eliciting opioid receptor-specific effects ${ }^{19,37}$, was reversed or prevented by the administration of low doses of naloxone $(0.2 \mathrm{mg} / \mathrm{kg}$ or less), and was mimicked by levorphanol but not by dextrorphan. Second, iontophoretic applications of morphine in the immediate vicinity of Purkinje cells reduced inhibition derived from the $\mathrm{LC}$ to an extent similar to that observed with systemic narcotic administration. This indicates that the blockade of LCinduced inhibition observed after systemic administration of morphine can occur independent of actions of the narcotic at receptor sites remote from LC noradrenergic synapses on Purkinje cells. Finally, administration of opiates either systemically or locally at the site of recording did not appreciably alter NE. induced inhibitions in firing elicited by iontophoretic applications of the neurotransmitter directly onto Purkinje cells. Alterations in the postsynaptic actions of NE owing to an antagonistic action of opiates at NE neuronal receptors are thus also unlikely to account for the blockade in LC-mediated noradrenergic inhibition demonstrated here. Taken together, these data argue strongly that the blockade of LC-in- hibitory action produced by morphine derives from an inhibition of NE release mediated by presynaptic opiate receptors on LC nerve terminals. The results further suggest that the activation of these presynaptic opiate receptors can lead to a functional impairment in noradrenergic transmission from LC to Purkinje cells in rat cerebellum.

Opiates and opioid peptides have now been shown to inhibit the release of neurotransmitters from noradrenergic nerve endings in slices prepared from rat cerebral cortex and hypothalamus ${ }^{30,36}$, areas which are relatively rich in stereospecific opiate binding sites $^{28,35}$, and the cerebellum ${ }^{22,36}$ where stereospecific binding of opiates is negligible ${ }^{1,28}$. The possibility that opiate receptors in the cerebellum are localized preferentially to LC nerve terminals (see above) could account for the fact that opiates have a specific effect on NE release in this region. Nevertheless, the cerebellum, in comparison with the cerebral cortex or hypothalamus, is virtually devoid of both endogenous opioids ${ }^{13}$ and of opioid-containing input that originates extrinsically ${ }^{14}$. This raises the issue regarding whether an endogenous ligand exists for presynaptic opioid receptors on LC noradrenergic terminals innervating the cerebellum. If enkephalin-like compounds are released in cerebellum either upon activation of noradrenergic LC afferents in situ or following electrical stimulation of brain slices, then naloxone might be expected to exert pharmacological effects by competing with these endogeneous ligands. However, previous experiments by Montel and co-workers ${ }^{22}$ failed to reveal any effect of naloxone on the electrically evoked release of NE from noradrenergic endings in rat cerebellar slices. The administration of naloxone was similarly found here to have little effect on NE-mediated inhibitions in Purkinje cell firing elicited by LC stimulation. Thus, it remains unclear to what extent presynaptic opiate receptors may be involved normally in the physiological regulation of cerebellar noradrenergic transmission.

\section{Antagonism of GABA-mediated responses by mor- phine}

An additional finding of the present study was that morphine blocked inhibitions in Purkinje cell firing elicited by activation of GABA-mediated input from local cerebellar interneurons. This effect of the nar- 
cotic was most likely due to a direct blockade of postsynaptic responses to GABA, since depressions in neuronal firing induced by iontophoretic application of the inhibitory amino acid were also blocked by morphine. These results are in agreement with earlier reports of antagonism of GABA-induced inhibition in olfactory tubercle neurons and spinal cord interneurons by iontophoretically applied morphine $^{6.7}$. In addition, Werz and MacDonald ${ }^{38}$ have recently shown by intracellular recording that morphine can directly antagonize the postsynaptic actions of GABA in cultured murine spinal cord neurons. These workers concluded that the antagonism of GABA responses by morphine was unlikely to be mediated by opiate receptors, since the effect was not produced by opioid peptides or antagonized by naloxone, nor was it highly stereospecific. The finding here that blockade of off-beam inhibition by morphine was not stereospecific and showed only weak naloxone-reversibility suggests that a similar nonopiate receptor-mediated mechanism may account for the blockade of Purkinje cell responses to GABA. Opiate alkaloids have been shown to displace $\left[{ }^{3} \mathrm{H}\right] \mathrm{GABA}$ from GABA receptor sites in homogenates of human cerebellum with comparatively low potencies $\left(\mathrm{IC}_{50}=250-400 \mu \mathrm{M}\right)^{6}$. Naloxone has also been reported to displace $\left[{ }^{3} \mathrm{H}\right] \mathrm{GABA}$ from GABA receptor sites in rat forebrain and cerebellum, with similar low potency ${ }^{6}$. Such an interaction of morphine at GABA receptors on rat cerebellar Purkinje cells could, therefore, account for the blockade of GABA-mediated inhibition observed here after systemic administration of the narcotic.

Finally, an antagonistic effect of morphine on the

\section{REFERENCES}

1 Atweh, S.F. and Kuhar, M.J., Autoradiographic localization of opiate receptors in rat brain. I. Spinal cord and lower medulla, Brain Research, 124 (1977) 53-67.

2 Basile, A.S. and Dunwiddie, T.V., Norepinephrine elicits both excitatory and inhibitory responses from Purkinje cells in the in vitro rat cerebellar slice, Brain Research, 296 (1984) 15-25.

3 Beckett, A.H. and Casy, A.F.. Synthetic analgesics: stereochemical considerations, J. Pharm. Pharmacol., 6 (1954) 986-999.

4 Bloom, F.E., Hoffer, B.J. and Siggins, G.R., Studies on norepinephrine-containing afferents to Purkinje cells of rat cerebellum. I. Localization of the fibers and their synapses, postsynaptic action of GABA could account for the enhancement in Purkinje cell responsiveness to parallel fiber activation. The excitations in Purkinje cell discharge evoked by parallel fiber activity are typically followed by a variable period of active inhibition mediated via input from GABA-containing interneurons activated by the initial parallel fiber volley. It is thought that through this arrangement of feedforward inhibition from local interneurons, the extent of Purkinje cell activity evoked by a given parallel fiber volley is limited in both time and space ${ }^{\gamma}$. This model would predict an increased firing of Purkinje cells to parallel fiber activation as a result of disinhibition by the narcotic, as was seen. Such disinhibitory effects, resulting from an antagonism of GABA-mediated synaptic inhibition, have been shown to underlie some of the convulsant and central excitatory actions of both moderate ${ }^{41}$ and relatively high doses of opiates ${ }^{6.9 .38}$. The present results were somewhat unusual in this regard in that an increased excitability of Purkinje cells to synaptic activation was apparent after administratrion of morphine in a range of doses indicative of an opioid receptor-mediated phenomenon ${ }^{3 \cdot 19,41}$. The significance of this finding to the mechanisms underlying the excitatory actions of opiates is currently under investigation.

\section{ACKNOWLEDGEMENTS}

This work was supported by USPHS Grant DA03365 and a research career development award from The Chicago Community Trust/Searle Scholars Program.
Brain Research, 25 (1971) 501-522.

5 Bradley, P.B. and Dray, A., Morphine and neurotransmitter substances: microiontophoretic study in the rat brainstem, Br. J. Pharmacol., 50 (1974) 47-55.

6 Dingledine, R., Iversen, L.L. and Breuker, E., Naloxone as a GABA antagonist: evidence from iontophoretic, receptor binding and convulsant studies, Eur. J. Pharmacol., 47 (1978) 19-27.

7 Dostrovsky, J. and Pomeranz, B., Morphine blockade of amino acid putative transmitters on cat spinal cord sensory interneurons, Nature (London) New Biol., 246 (1973) 222-224.

8 Eccles, J.C., Ito, M. and Szentogothai, J., The Cerebellum as a Neuronal Machine, Springer-Verlag, New York, 1967, p. 335 . 
9 Frenk, H., Urca, G. and Liebeskind, J.C., Epileptic properties of leucine- and methionine-enkephalin: comparison with morphine and reversibility by naloxone, Brain $R e$ search, 147 (1978) 327-337.

10 Garcin, F, and Coyle, J.T., Effects of perinatal 6-hydroxydopamine treatment on opiate receptor distribution in adult brain, Commun. Psychopharmacol, 2 (1977) $283-290$

11 Hoffer, B.J., Siggins, G.R. and Bloom, F.E., Studies on norepinephrine-containing afferents to Purkinje cells of rat cerebellum. II. Sensitivity of Purkinje cells to norepinephrine and related substances administered by microiontophoresis, Brain Research, 25 (1971) 523-534.

12 Hoffer, B.J., Siggins, G.R., Oliver, A.P. and Bloom, F.E., Activation of the pathway from locus coeruleus to rat cerebellar Purkinje neurons: pharmacological evidence of noradrenergic central inhibition, J. Pharmacol. Exp. Ther., 184 (1973) 553-569.

13 Hughes, J., Kosterlitz, H.W. and Smith, T.W., The distribution of methionine-enkephalin and leucine-enkephalin in the brain and peripheral tissues, Br. J. Pharmacol., 61 (1977) 639-647.

14 Khachaturian, H., Lewis, M.E., Schäfer, M.K.-H. and Watson, S.J., Anatomy of the CNS opioid systems, TINS, 8 (1985) 111-119.

15 Kimoto, Y., Tohyama, M., Satoh, K., Sakumoto, T., Takahashi, Y. and Shimizu, N., Fine structure of rat cerebellar noradrenaline terminals as visualized by potassium permanganate 'in situ perfusion' fixation method, Neuroscience, 6 (1981) 47-58.

16 König, J.F.R. and Klippel, R.A., The Rat Brain: A Stereotaxic Atlas of the Forebrain and Lower Parts of the Brain Stem, Williams and Wilkins, Baltimore, 1963, p. 162.

17 Langer, S.Z., Presynaptic regulation of the release of catecholamines, Pharmacol. Rev., 32 (1981) 337-362.

18 Llorens, C., Martres, M.P., Baudry, M. and Schwartz, J.C., Hypersensitivity to noradrenaline in cortex after chronic morphine: relevance to tolerance and dependence, Nature (London), 274 (1978) 603-605.

19 Martin, W.R., Pharmacology of opioids, Pharmacol. Rev., 35 (1984) 285-323.

20 Moises, H.C., Waterhouse, B.D. and Woodward, D.J., Locus coeruleus stimulation potentiates Purkinje cell responses to afferent input: the climbing fiber system, Brain Research, 222 (1981) 43-64.

21 Moises, H.C. and Woodward, D.J., Potentiation of GABA inhibitory action in cerebellum by locus coeruleus stimulation, Brain Research, 182 (1980) 327-344.

22 Montel, H., Starke, K. and Taube, H.D., Influence of morphine and naloxone on the release of noradrenaline from rat cerebellar cortex slices, Naunyn Schmiedeberg's Arch. Pharmacol., 288 (1975) 427-433.

23 Mulder, A.H., Frankhuyzen, A.L., Stoof, J.C., Wemer, J. and Schoffelmeer, A.N.M., Catecholamine receptors, opiate receptors and presynaptic modulation of neurotransmitter release in the brain. In E. Usdin, A. Carlsson, A. Dahlström and J. Engel (Eds.), Catecholamines: Neuropharmacology and Central Nervous System - Theoretical Aspects, A.R. Liss, New York, 1984, pp. 47-58.

24 Nakamura, S., Tepper, J.M., Young, S.J., Ling, N. and
Groves, P.M., Noradrenergic terminal excitability: effects of opioids., Neurosci. Lett., 30 (1982) 57-62.

25 North, R.A. and Williams, J.T., How do opiates inhibit neurotransmitter release? TINS, 6 (1983) 337-339.

26 Olson, L. and Fuxe, K., On the projections from the locus coeruleus noradrenaline neurons: the cerebellar innervation, Brain Research, 28 (1971) 165-171.

27 Pepper, C.M. and Henderson, G., Opiates and opioid peptides hyperpolarize locus coeruleus neurons in vitro, Science, 209 (1980) 394-396.

28 Pert, C.B., Kuhar, M.J. and Snyder, S.H., Opiate receptor: autoradiographic localization in rat brain, Proc. Natl. Acad. Sci. U.S.A., 73 (1976) 3729-3733.

29 Sasa, M., Munekiyo, K. and Takaori, S., Morphine interference with noradrenaline-mediated inhibition from the locus coeruleus, Life Sci., 17 (1979) 1373-1380.

30 Schoffelmeer, A.N.M. and Mulder, A.H., Differential control of $\mathrm{Ca}^{2+}$-dependent $\left[{ }^{3} \mathrm{H}\right]$ noradrenaline release from rat brain slices through presynaptic opiate receptors and $\alpha_{2}$ adrenoceptors, Eur. J. Pharmacol., 87 (1983) 449-458.

31 Seeman, P., Chau-Wong, M. and Moyyen, S., The membrane binding of morphine, diphenylhydantoin and tetrahydroccannabinol, Can. J. Physiol. Pharmacol, 50 (1972) $1193-1200$

32 Segal, M., Morphine and enkephalin interactions with putative neurotransmitters in rat hippocampus, Neuropharmacology, 16 (1977) 587-592.

33 Siggins, G.R., Hoffer, B.J., Oliver, A.P. and Bloom, F.E., Activation of a central noradrenergic projection to cerebellum, Nature (London), 233 (1971) 481-483.

34 Siggins, G.R., Oliver, A.P. Hoffer, B.J. and Bloom, F.E., Cyclic adenosine monophosphate and norepinephrine : effects on transmembrane properties of cerebellar Purkinje cells, Science, 171 (1971) 192-194.

35 Squires, R.F. and Braestrup, C., Characteristics and regional distributions of two distinct $\left[{ }^{3} \mathrm{H}\right]$ naloxone binding sites in the rat brain, $J$. Neurochem., 30 (1978) 231-236.

36 Taube, H.D., Starke, K. and Borowski, E., Presynaptic receptor systems on the noradrenergic neurons of rat brain, Naunyn Schmiedeberg's Arch. Pharmacol., 299 (1977) 123-141.

37 Waterfield, A., Smokcum, R., Hughes, J., Kosterlitz, H. and Henderson, G., In vitro pharmacology of opioid peptides, enkephalins and endorphins, Eur. J. Pharmacol., 43 (1977) 107-116.

38 Werz, M.A. and MacDonald, R.L., Opiate alkaloids antagonize postsynaptic glycine and GABA responses: correlaton with convulsant action, Brain Research, 236 (1982) 107-119.

39 Williams, J.T., Egan, T.M. and North, R.A., Enkephalin opens potassium channels on mammalian central neurones, Nature (London), 299 (1982) 74-77.

40 Yamamoto, T., Ishikawa, M. and Tanaka, C., Catecholaminergic terminals in the developing and adult rat cerebellum, Brain Research, 132 (1977) 355-361.

41 Zieglgänsberger, W., French, E.D., Siggins, G.R. and Bloom, F.E., Opioid peptides may excite hippocampal pyramidal neurons by inhibiting adjacent inhibitory interneurons, Science, 205 (1979) 415-417. 